\title{
In Vitro Activity of Loracarbef (LY163892), a New Oral Carbacephem Antimicrobial Agent, against Respiratory Isolates of Haemophilus influenzae and Moraxella catarrhalis
}

\author{
GARY V. DOERN,* RAYMOND VAUTOUR, DOUGLAS PARKER, TRACEY TUBERT, AND BRENDA TORRES \\ Department of Clinical Microbiology and Division of Infectious Diseases, University of Massachusetts Medical Center, \\ Worcester, Massachusetts 01655
}

Received 4 January 1991/Accepted 17 April 1991

\begin{abstract}
The in vitro activity of a new orally administered carbacephem analog of cefaclor, loracarbef (LY163892), was compared with those of cefaclor and several other oral antimicrobial agents against recent clinical isolates of Haemophilus influenzae and Moraxella catarrhalis. Loracarbef was found to be slightly more active than cefaclor against $\boldsymbol{H}$. influenzae and had activity essentially equivalent to that of cefaclor for $M$. catarrhalis. Resistance to loracarbef was uncommon and was noted only with rare $\beta$-lactamase-producing strains of $\boldsymbol{H}$. influenzae. On the basis of these observations, loracarbef may be of utility in the management of localized, non-life-threatening infections caused by $H$. influenzae and $M$. catarrhalis.
\end{abstract}

Loracarbef (LY163892) is a new orally administered carbacephem class antimicrobial agent in which the sulfur atom of the dihydrothiazine ring of cefaclor has been replaced with a carbon atom. The result of this substitution is that loracarbef is more stable in serum than is cefaclor. Loracarbef is the first carbacephem class beta-lactam antimicrobial agent to undergo clinical development. Its chemical name is $(6 R, 7 S)-7-[(R)$-2-amino-2-phenylacetamido]-3-chloro-8-oxo1-azabicyclo-[4.2.0]oct-2-ene-2-carboxylic acid monohydrate $\left(\mathrm{C}_{16} \mathrm{O}_{4} \mathrm{~N}_{3} \mathrm{H}_{16} \mathrm{Cl} \cdot \mathrm{H}_{2} \mathrm{O}\right)$. The molecular weight of loracarbef is 367.8 .

Since loracarbef will be marketed as an oral agent for use in the management of respiratory tract infections such as acute otitis media, sinusitis, and bacterial bronchopulmonary infections (10a), and since, as a beta-lactam antimicrobial agent, its activity against $\beta$-lactamase-producing organisms is of concern, the in vitro activity of loracarbef was assessed against Haemophilus influenzae and Moraxella catarrhalis, two frequent causes of these infections which often produce $\beta$-lactamase. The in vitro activity of loracarbef was compared with those of several other commonly used oral antimicrobial agents: ampicillin, amoxicillin-clavulanate, cefaclor, cefuroxime, cefixime, trimethoprim-sulfamethoxazole, erythromycin, and the combination erythromycin-sulfisoxazole. In addition, cephalothin, chloramphenicol, and sulfisoxazole (alone) were also tested.

A total of 307 clinical isolates of $H$. influenzae and 146 clinical isolates of $M$. catarrhalis were examined. Isolates were obtained from patients in the United States who were enrolled in multicenter clinical trials of loracarbef during 1989. The disease associations of the isolates and the number of study centers contributing strains are listed in Table 1. In patients with otitis media, isolates were recovered from tympanocentesis fluid. Sinus aspirates were the source of isolates from patients with acute maxillary sinusitis. In patients with acute bronchitis, acute purulent exacerbation of chronic bronchitis, or pneumonia, isolates were usually obtained from expectorated sputa that had been judged to be satisfactory on the basis of Gram-stained smears. All sus-

\footnotetext{
* Corresponding author.
}

ceptibility testing was performed in one laboratory (University of Massachusetts Medical Center).

A broth microdilution MIC procedure was used to determine the MICs of 12 antimicrobial agents $(3,10)$. A final volume of $100 \mu \mathrm{l}$ per well was used with a final inoculum size of ca. $5 \times 10^{5} \mathrm{CFU} / \mathrm{ml}$. Microdilution trays were incubated for 22 to $24 \mathrm{~h}$ at $35^{\circ} \mathrm{C}$ in ambient air prior to determination of MICs. Haemophilus Test Medium broth prepared in-house was used for MIC determinations with both $\boldsymbol{H}$. influenzae and $M$. catarrhalis (7). Extensive preliminary studies demonstrated concordance between microdilution MIC results obtained with $M$. catarrhalis when it was tested in Haemophilus Test Medium broth versus those when it was tested in cation-adjusted Mueller-Hinton broth (unpublished data).

The antimicrobial agents tested in this study were obtained from their respective manufacturers as reagent-grade powders. These included ampicillin (Bristol-Myers); amoxicillin-clavulanate (Smith-Kline Beecham); cephalothin, cefaclor, and loracarbef (Lilly); cefuroxime (Glaxo); cefixime (Lederle); chloramphenicol (Parke-Davis); trimethoprim and sulfamethoxazole (Hoffmann-LaRoche); and erythromycin (Abbott). The range of concentrations tested for each antimicrobial agent was such that most test strains yielded on-range MIC values, i.e., defined MICs rather than values less than or greater than the specific concentrations tested. Five strains of $\boldsymbol{H}$. influenzae, including ATCC 49247 and ATCC 10211, were used as daily controls. Three strains of $M$. catarrhalis, all previously extensively characterized in our laboratory, were also used as daily controls. $\beta$-Lactamase production was assessed with all study isolates by use of a chromogenic cephalosporin assay (9) which used nitrocefin-impregnated filter paper disks (cefinase disks; BectonDickinson Microbiology Systems, Cockeysville, Md.).

All MIC determinations were performed twice on different days, and the results were averaged to achieve an assigned MIC for a given organism-antimicrobial agent combination. When duplicate MICs varied by one twofold concentration increment, the higher MIC was taken as the assigned MIC. Among a total of 3,684 duplicate MIC determinations with $H$. influenzae, the two results were the same or varied by one or two twofold concentration increments in $3,448(94 \%)$, 
TABLE 1. Description of sources of clinical isolates of $H$. influenzae and $M$. catarrhalis

\begin{tabular}{clcc}
\hline \multirow{2}{*}{$\begin{array}{c}\text { No. of } \\
\text { contributing } \\
\text { study centers }\end{array}$} & \multicolumn{1}{c}{$\begin{array}{c}\text { Disease } \\
\text { association }\end{array}$} & \multicolumn{2}{c}{ No. of strains of ${ }^{a}:$} \\
\cline { 3 - 4 } & & H. influenzae & M. catarrhalis \\
\hline 15 & Acute otitis media & $105(36,34)$ & $59(54,91)$ \\
4 & Acute maxillary sinusitis & $17(3,18)$ & $3(3,100)$ \\
74 & Bronchitis & $147(28,19)$ & $84(57,68)$ \\
6 & Pneumonia & $38(5,13)$ & 0 \\
& Total & $307(72,23)$ & $146(114,78)$ \\
\hline
\end{tabular}

${ }^{a}$ Numbers in parentheses refer to the number, percentage of strains that were $\beta$-lactamase positive.

$202(5 \%)$, and $34(0.9 \%)$ cases, respectively. With $M$. catarrhalis $(1,752$ duplicate MIC determinations), the following was observed: no difference, 1,677 cases $(96 \%)$; a difference of one dilution, 62 cases (3\%); and a difference of two dilutions, 13 cases $(0.7 \%)$.

As seen in Table 2, loracarbef was active against both $\beta$-lactamase-positive and -negative strains of $\boldsymbol{H}$. influenzae. The geometric mean loracarbef MICs for $\beta$-lactamase-positive and -negative strains of $\boldsymbol{H}$. influenzae were 1.4 and 2.0 $\mu \mathrm{g} / \mathrm{ml}$, respectively. If a loracarbef $\mathrm{MIC}$ of $\leq 8.0 \mu \mathrm{g} / \mathrm{ml}$ was used to define strains of $\boldsymbol{H}$. influenzae as being susceptible, 87 and $95 \%$ of $\beta$-lactamase-positive and -negative strains, respectively, were found to be loracarbef susceptible. Use of an $\mathrm{MIC}$ of $\leq 8.0 \mu \mathrm{g} / \mathrm{ml}$ to define the susceptible category with loracarbef seems appropriate, insofar as this same criterion has been applied to cefaclor when tested against $\boldsymbol{H}$. influenzae (10). Furthermore, peak achievable levels of loracarbef in plasma are typically ca. twofold higher than this breakpoint when the drug is administered orally in standard doses (i.e., $200 \mathrm{mg}$ ) (8). Of $73 \beta$-lactamase-positive strains, for 4 strains $(6 \%)$ loracarbef MICs were $\geq 32 \mu \mathrm{g} / \mathrm{ml}$, and thus, the strains would have been categorized as resistant. Loracarbef resistance was not noted with strains of $\boldsymbol{H}$. influenzae that lacked $\beta$-lactamase. Among the cephalosporins tested, cephalothin and cefaclor had essentially comparable activities against $\boldsymbol{H}$. influenzae. Both were slightly less active than loracarbef, which was, in turn, less active than cefuroxime. Cefixime was clearly the most active of the cephalosporins tested against $H$. influenzae. As seen in Table 3, when compared on a strain-by-strain basis, loracarbef MICs were typically about one twofold concentration increment lower than the corresponding cefaclor MICs for both $\beta$-lactamase-positive and -negative strains of $\boldsymbol{H}$. influenzae.

TABLE 2. In vitro activities of loracarbef and other selected antimicrobial agents against $H$. influenzae and $M$. catarrhalis

\begin{tabular}{|c|c|c|c|c|c|c|c|c|}
\hline \multirow{3}{*}{ Antimicrobial agent } & \multicolumn{8}{|c|}{ Results with ${ }^{a}$ : } \\
\hline & \multicolumn{4}{|c|}{ H. influenzae } & \multicolumn{4}{|c|}{ M. catarrhalis } \\
\hline & $\begin{array}{c}\beta- \\
\text { Lactamase }\end{array}$ & $\begin{array}{c}\mathrm{MIC}_{50} \\
(\mu \mathrm{g} / \mathrm{ml})\end{array}$ & $\begin{array}{l}\mathrm{MIC}_{90} \\
(\mu \mathrm{g} / \mathrm{ml})\end{array}$ & $\begin{array}{l}\text { MIC range } \\
(\mu \mathrm{g} / \mathrm{ml})\end{array}$ & $\begin{array}{c}\beta- \\
\text { Lactamase }\end{array}$ & $\begin{array}{c}\mathrm{MIC}_{s 0} \\
(\mu \mathrm{g} / \mathrm{ml})\end{array}$ & $\begin{array}{l}\mathrm{MIC}_{90} \\
(\mu \mathrm{g} / \mathrm{ml})\end{array}$ & $\begin{array}{l}\text { MIC range } \\
(\mu \mathrm{g} / \mathrm{ml})\end{array}$ \\
\hline Ampicillin & $\begin{array}{l}+ \\
-\end{array}$ & $\begin{array}{l}16 \\
\leq 0.25\end{array}$ & $\begin{array}{l}32 \\
0.5\end{array}$ & $\begin{array}{c}4->32 \\
\leq 0.25-16\end{array}$ & $\begin{array}{l}+ \\
-\end{array}$ & $\begin{array}{c}2.0 \\
\leq 0.25\end{array}$ & $\begin{aligned} & 4.0 \\
\leq & 0.25\end{aligned}$ & $\begin{aligned} & 0.25-4.0 \\
\leq & 0.25\end{aligned}$ \\
\hline Amoxicillin-clavulanate $(2: 1)^{b}$ & $\begin{array}{l}+ \\
-\end{array}$ & $\begin{array}{l}1.0 \\
0.5\end{array}$ & $\begin{array}{l}2.0 \\
1.0\end{array}$ & $\begin{array}{l}0.5->8.0 \\
0.12-4.0\end{array}$ & $\begin{array}{l}+ \\
-\end{array}$ & $\begin{array}{r}0.12 \\
\leq 0.06\end{array}$ & $\begin{array}{r}0.25 \\
\leq 0.06\end{array}$ & $\begin{array}{l}\leq 0.06-0.5 \\
\leq 0.06-0.12\end{array}$ \\
\hline Cephalothin & $\begin{array}{l}+ \\
-\end{array}$ & $\begin{array}{l}2.0 \\
2.0\end{array}$ & $\begin{array}{l}16 \\
8.0\end{array}$ & $\begin{array}{l}\leq 0.5->64 \\
\leq 0.5-32\end{array}$ & $\begin{array}{l}+ \\
-\end{array}$ & $\begin{aligned} & 4.0 \\
\leq & 0.12\end{aligned}$ & $\begin{array}{l}8.0 \\
0.25\end{array}$ & $\begin{array}{r}2.0-8.0 \\
\leq 0.12-0.25\end{array}$ \\
\hline Cefaclor & $\begin{array}{l}+ \\
-\end{array}$ & $\begin{array}{l}4.0 \\
2.0\end{array}$ & $\begin{array}{l}16 \\
8.0\end{array}$ & $\begin{array}{l}1.0->32 \\
0.5->32\end{array}$ & $\begin{array}{l}+ \\
-\end{array}$ & $\begin{array}{c}1.0 \\
\leq 0.25\end{array}$ & $\begin{array}{c}2.0 \\
\leq \\
0.25\end{array}$ & $\begin{array}{l}\leq 0.25-2.0 \\
\leq 0.25\end{array}$ \\
\hline Loracarbef & $\begin{array}{l}+ \\
-\end{array}$ & $\begin{array}{l}2.0 \\
2.0\end{array}$ & $\begin{array}{l}16 \\
8.0\end{array}$ & $\begin{array}{r}0.5->32 \\
\leq 0.25->32\end{array}$ & $\begin{array}{l}+ \\
-\end{array}$ & $\begin{array}{c}1.0 \\
\leq 0.25\end{array}$ & $\begin{aligned} & 2.0 \\
\leq & 0.25\end{aligned}$ & $\begin{array}{l}\leq 0.25-4.0 \\
\leq 0.25\end{array}$ \\
\hline Cefuroxime & $\begin{array}{l}+ \\
-\end{array}$ & $\begin{array}{l}0.5 \\
1.0\end{array}$ & $\begin{array}{l}2.0 \\
2.0\end{array}$ & $\begin{array}{r}0.5-8.0 \\
\leq 0.12-8.0\end{array}$ & $\begin{array}{l}+ \\
-\end{array}$ & $\begin{array}{l}1.0 \\
0.5\end{array}$ & $\begin{array}{l}2.0 \\
0.5\end{array}$ & $0.25-4.0$ \\
\hline Cefixime & $\begin{array}{l}+ \\
-\end{array}$ & $\begin{array}{l}\leq 0.03 \\
\leq 0.03\end{array}$ & $\begin{array}{l}0.06 \\
0.06\end{array}$ & $\begin{array}{l}\leq 0.03->4 \\
\leq 0.03-1.0\end{array}$ & $\begin{array}{l}+ \\
-\end{array}$ & $\begin{array}{r}0.12 \\
\leq 0.03\end{array}$ & $\begin{aligned} & 0.5 \\
\leq & 0.03\end{aligned}$ & $\begin{array}{l}\leq 0.03-0.5 \\
\leq 0.03-0.25\end{array}$ \\
\hline Chloramphenicol & NA & 1.0 & 2.0 & $\leq 0.5-32$ & NA & 0.5 & 1.0 & $0.5-1.0$ \\
\hline Trimethoprim-sulfamethoxazole $(1: 19)^{c}$ & NA & 0.12 & 0.5 & $\leq 0.03-16$ & NA & $\leq 0.12$ & $\leq 0.5$ & $\begin{array}{l}\leq 0.12-1.0 \\
\leq 0.5\end{array}$ \\
\hline Sulfisoxazole & NA & $>64$ & $>64$ & $2.0->64$ & NA & 16 & $>64$ & $\leq 0.12->64$ \\
\hline Erythromycin-sulfisoxazole $(1: 64)^{d}$ & NA & 2.0 & 4.0 & $0.12-8.0$ & NA & $\leq 0.12$ & 0.25 & $\leq 0.12-1.0$ \\
\hline
\end{tabular}

${ }^{a} \mathrm{MIC}_{50}$ and $\mathrm{MIC}_{90}$, MIC for 50 and $90 \%$ of isolates, respectively. Among the 307 strains of $\boldsymbol{H}$. influenzae tested, 72 produced $\beta$-lactamase. Among the 146 strains of $M$. catarrhalis tested, 114 produced $\beta$-lactamase. NA, not available.

${ }^{b}$ Values refer to the amoxicillin concentration.

$c$ Values refer to the trimethoprim concentration.

d Values refer to the erythromycin concentration. 
TABLE 3. Comparison of in vitro activities of loracarbef and cefaclor against $\boldsymbol{H}$. influenzae and $\boldsymbol{M}$. catarrhalis

\begin{tabular}{|c|c|c|c|}
\hline \multirow{3}{*}{$\begin{array}{l}\text { Loracarbef MIC } \\
\qquad(\mu \mathrm{g} / \mathrm{ml})\end{array}$} & \multicolumn{3}{|c|}{ Geometric mean cefaclor MIC $(\mu \mathrm{g} / \mathrm{ml})$ obtained with ${ }^{a}$ : } \\
\hline & \multicolumn{2}{|c|}{ H. influenzae } & \multirow[b]{2}{*}{$\begin{array}{c}\text { M. catarrhalis, } \\
\beta \text {-lactamase positive }{ }^{b}\end{array}$} \\
\hline & $\begin{array}{c}\beta- \\
\text { Lactamase } \\
\text { postive }\end{array}$ & $\begin{array}{c}\beta- \\
\text { Lactamase } \\
\text { negative }\end{array}$ & \\
\hline$\geq 32$ & $\geq 32$ (4) & $\geq 32(2)$ & \\
\hline 16 & $28.8(5)$ & $16(10)$ & \\
\hline 8.0 & $13.6(10)$ & $11.2(20)$ & \\
\hline 4.0 & $6.5(8)$ & $5.3(32)$ & $2.0(2)$ \\
\hline 2.0 & $2.9(30)$ & $3.0(75)$ & $1.5(24)$ \\
\hline 1.0 & $1.8(13)$ & $1.9(84)$ & $1.0(75)$ \\
\hline 0.5 & $2.0(2)$ & $0.9(12)$ & $0.6(22)$ \\
\hline$<0.25$ & & & $<0.25(2)$ \\
\hline
\end{tabular}

${ }^{a}$ Numbers in parentheses represent the number of strains with the indicated loracarbef MIC.

${ }^{b}$ For all $32 \beta$-lactamase-negative strains of $M$. catarrhalis, cefaclor and loracarbef MICs were $<0.25 \mu \mathrm{g} / \mathrm{ml}$.

Among the other antimicrobial agents examined in this investigation, the combination amoxicillin-clavulanate was highly active against both $\beta$-lactamase-positive and -negative strains. Three strains of $\boldsymbol{H}$. influenzae with chloramphenicol MICs of $\geq 8.0 \mu \mathrm{g} / \mathrm{ml}$ were classified as being resistant by the criteria of the National Committee for Clinical Laboratory Standards (10). One strain, for which the chloramphenicol MIC was $4.0 \mu \mathrm{g} / \mu \mathrm{l}$, was considered intermediate. All four of these strains were shown to produce chloramphenicol acetyltransferase. Trimethoprim-sulfamethoxazole was highly active. MICs of $\leq 0.5 / 9.5 \mu \mathrm{g} / \mathrm{ml}$ were observed with $96 \%$ of strains; these strains were thus categorized as susceptible (10). Erythromycin and sulfisoxazole alone demonstrated poor activity against $\boldsymbol{H}$. influenzae; however, when combined in a proportion of 1:64 (erythromycin:sulfisoxazole), the activity of erythromycin was clearly enhanced. In general, these observations are consistent with the results of previous surveillance studies that have examined the prevalence of antibiotic resistance among clinical isolates of $\boldsymbol{H}$. influenzae $(1,2,6)$.

Of note were 3 of $235 \beta$-lactamase-negative strains of $H$. influenzae, one each for which ampicillin MICs were 4.0, 8.0 , and $16 \mu \mathrm{g} / \mathrm{ml}$, which were found to be ampicillin resistant, even though they lacked detectable $\beta$-lactamase. All three of these strains were non-type $b$ and were recovered from expectorated sputum specimens from adult patients with acute purulent exacerbation of chronic bronchitis. The amoxicillin-clavulanate MICs for these strains were $2.0 \mu \mathrm{g} / \mathrm{ml}$ (one case) and $4.0 \mu \mathrm{g} / \mathrm{ml}$ (two cases). For two of these three ampicillin-resistant, $\beta$-lactamase-negative strains of $H$. influenzae, the loracarbef MIC was $16 \mu \mathrm{g} / \mathrm{ml}$; for the third strain, the loracarbef MIC was $8.0 \mu \mathrm{g} / \mathrm{ml}$.

Also of interest was the observation that a much higher percentage of isolates of $\boldsymbol{H}$. influenzae from patients with acute otitis media produced $\beta$-lactamase than did those from patients with sinusitis or bronchopulmonary infections (Table 1). Two previous surveillance studies in the United States have revealed the same pattern $(2,6)$.

As seen in Table 2, loracarbef was also active against clinical isolates of $M$. catarrhalis. Although the $\beta$-lactamase of $M$. catarrhalis appeared to influence loracarbef MICs, if an MIC of $\geq 32 \mu \mathrm{g} / \mathrm{ml}$ was used to define resistance, no resistance was noted among either $\beta$-lactamase-positive or -negative strains. Among the cephalosporins tested in this study, loracarbef was more active than cephalothin, slightly more active than cefuroxime, essentially as active as cefaclor, and less active than cefixime. The equivalence of the activities of loracarbef and cefaclor for $M$. catarrhalis was apparent when MIC data were analyzed collectively (Table 2) and also when the MICs for these two agents were compared on a strain-by-strain basis (Table 3). The high prevalence of $\beta$-lactamase-producing strains noted in the current study is consistent with the results of others (6).

Among the other antimicrobial agents tested against $M$. catarrhalis, resistance was noted only with ampicillin, and then only with $\beta$-lactamase-positive strains. As has been described previously $(4-6,11)$, a large number of $\beta$-lactamase-producing strains of $M$. catarrhalis in the present study appeared to be susceptible to ampicillin, despite $\beta$-lactamase production. Specifically, for 26 of $114 \beta$-lactamase-positive strains (22.8\%), ampicillin MICs were $\leq 0.25$ $\mu \mathrm{g} / \mathrm{ml}$. It is likely that these strains produce the BRO-2- or 1908-type $\beta$-lactamase, as opposed to the more common BRO-1- or Ravasio-type enzyme (11). Also of interest was the observation that not all strains of $M$. catarrhalis appeared to be susceptible to trimethoprim-sulfamethoxazole. High-level resistance (i.e., MICs of $>4.0 / 76 \mu \mathrm{g} / \mathrm{ml}$ ) was not noted. However, if the interpretive criteria of the National Committee for Clinical Laboratory Standards for trimethoprim-sulfamethoxazole, when tested against $\boldsymbol{H}$. influenzae, were applied to $M$. catarrhalis, then $3 \%$ of strains tested (i.e., 5 of 146 strains in total) would have been categorized as having intermediate susceptibilities to trimethoprim-sulfamethoxazole, with MICs of $1.0 / 19 \mu \mathrm{g} / \mathrm{ml}(10)$.

In conclusion, the results of this study indicate that the new orally administered carbacephem antimicrobial agent loracarbef is at least as active as cefaclor against two common respiratory tract pathogens, $H$. influenzae and $M$. catarrhalis. It is likely, therefore, that loracarbef will prove to have utility in the management of selected infections caused by these two organisms. These include acute otitis media, acute sinusitis, and selected bronchopulmonary infections. Furthermore, the results of previous studies describing the in vitro activities of various oral antimicrobial agents against $H$. influenzae and $M$. catarrhalis were consistent with the results obtained in this investigation.

This study was supported by a grant from Eli Lilly \& Co., Indianapolis, Ind.

The secretarial assistance of Helen Saillant was greatly appreciated.

\section{REFERENCES}

1. Doern, G. V., J. H. Jorgensen, C. Thornsberry, D. A. Preston, and the Haemophilus influenzae Surveillance Group. 1986. Prevalence of antimicrobial resistance among clinical isolates of Haemophilus influenzae: a collaborative study. Diagn. Microbiol. Infect. Dis. 4:95-107.

2. Doern, G. V., J. H. Jorgensen, C. Thornsberry, D. A. Preston, T. Tubert, J. S. Redding, and L. A. Maher. 1988. National collaborative study of the prevalence of antimicrobial resistance among clinical isolates of Haemophilus influenzae. Antimicrob. Agents Chemother. 32:180-185.

3. Doern, G. V., J. H. Jorgensen, C. Thornsberry, and H. Snapper. 1990. Disk diffusion susceptibility testing of Haemophilus influenzae using Haemophilus Test Medium. Eur. J. Clin. Microbiol. Infect. Dis. 9:329-336.

4. Doern, G. V., and T. Tubert. 1987. Disk diffusion susceptibility testing of Branhamella catarrhalis with ampicillin and seven other antimicrobial agents. Antimicrob. Agents Chemother. 31:1519-1523.

5. Doern, G. V., and T. A. Tubert. 1987. Detection of $\beta$-lactamase 
activity among clinical isolates of Branhamella catarrhalis with six different $\beta$-lactamase assays. J. Clin. Microbiol. 25:1380 1383.

6. Jorgensen, J. H., G. V. Doern, L. A. Maher, A. W. Howell, and J. S. Redding. 1990. Antimicrobial resistance among respiratory isolates of Haemophilus influenzae, Moraxella catarrhalis and Streptococcus pneumoniae in the United States. Antimicrob. Agents Chemother. 34:2075-2080.

7. Jorgensen, J. H., J. S. Redding, L. A. Maher, and A. W. Howell. 1987. Improved medium for antimicrobial susceptibility testing of Haemophilus influenzae. J. Clin. Microbiol. 25:2105-2113.

8. Eli Lilly \& Co. Data on file. Eli Lilly \& Co., Indianapolis, Ind.
9. Montgomery, K., L. Raymundo, Jr., and W. L. Drew. 1979. Chromogenic cephalosporin spot test to detect $\beta$-lactamase in clinically significant bacteria. J. Clin. Microbiol. 9:205-207.

10. National Committee for Clinical Laboratory Standards. 1980. Methods for dilution antimicrobial susceptibility tests for bacteria that grow aerobically. Approved standard M7-A2. National Committee for Clinical Laboratory Standards, Villanova, $\mathrm{Pa}$.

10a.Therasse, D. Personal communication.

11. Wallace, R. J., D. R. Nash, and V. A. Steingrube. 1990. Antibiotic susceptibilities and drug resistance in Moraxella (Branhamella) catarrhalis. Am. J. Med. 88:46S-51S. 